\title{
LESSONS FROM A DROPPED ICT CURRICULUM DESIGN PROJECT: A RETROSPECTIVE VIEW
}

\author{
Roohollah Honarvar \\ AVEC Company
}

\begin{abstract}
Developing competent human resources is of crucial importance to policy makers aiming to move towards an information society. Universities are often designated the task of training Information Technology/Systems (IT/S) professionals for the economy of the future. This chapter critically reflects upon a dropped ICT curriculum design project which was to be used in ten Iranian universities. It aims to draw the attention of policy makers to the importance of practical considerations in issuing human resource development policies. The chapter focuses on the challenges of IT/S professionals' training to the centralised higher education system, as well as the challenge of providing social skills for IT/S professionals and the importance of national language. An analysis is given of the implicit assumptions behind Iran's national ICT policies and the deficiencies of those policies with regard to these challenges. Some practical recommendations and summary conclude the chapter.
\end{abstract}

Keywords: Developing countries, higher education, curriculum design, IT/S professionals' training, national ICT development policy

\section{Introduction}

Developing competent human resources is of vital importance to policy makers aiming to move towards an information society. Four categories of people in need of ICT education or training are identified within the literature: the general public, the policy makers and managers at the governmental and organisational levels, technology users, and IT/S professionals [18]. This last group consists of professionals in different jobs with the primary role of creating information products/services in the society. Thus, they are the most important forces in the actual development of ICT within the country. Due to the high level of specialised education and training needed, universities are often designated the task of training these IT/S professionals (see for example [3, 5]).

As the first decade of the twenty first century comes to its end, ICT curriculum has been integrated into the educational programmes of the universities in most developed countries (see also [16]). The situation is much more heterogeneous in 
the developing countries. In Asia, for instance, some pioneering countries (e.g. India, Malaysia, and Singapore) have become to some extent "powerful" players in the global information society by relying on their IT/S professionals, while some others (e.g. Nepal, Philippines, and central Asian countries) are just taking the first steps. More specifically, most countries do have a policy regarding the training of IT/S professionals ${ }^{1}$, but the scope and depth of these policies vary considerably from one to another. Policy makers can share their experiences in the implementation of IT/S professionals' training policy to the advantage of their nations [6]. ${ }^{2}$ This is highlighted when one notes the relatively diminutive size of literature in this area of ICT policy.

Caryannis and Sipp [3] emphasise the need for renewing the educational system of most developing countries at the university level to become up-to-date and "more responsive to the ever-changing demands of the Knowledge Economy". This chapter discusses the practical challenges raised during the implementation of Iran's IT/S professionals' training policy (hereafter referred to as IT/SPTP), part of which was to design a standard ICT curriculum. The curriculum was to be implemented as a pilot project in ten Iranian state universities. The issues that emerged almost brought the project to a halt. Finally, the project, with a 350.000 dollars budget, was abandoned without any significant achievements. This was despite the great enthusiasm and ambition behind the project and the voluminous efforts and studies by the project team, to which the author was a modest contributor.

The rest of chapter is structured as follows. First, the reader is introduced to the context of Iran's national ICT policies within which IT/SPTP was formed and the idiosyncrasies of the country's university system. Then the case is described in terms of the steps taken by the project team pointing out the questions considered in each step and solutions offered. An analysis of the issues and obstacles which in one way or another insinuated the impossibility of reaching the final result is followed by a discussion of alternative possible solutions and an analysis of implicit assumptions behind the national IT/SPTP. This leads to some practical recommendations for policy makers. The conclusion highlights the main points addressed in the chapter.

\section{The context}

Iran's National ICT agenda, usually known as TAKFA- Extension of Application of ICT in Iran- was established in 2002. The aim is to develop and maintain an advanced technological environment that will support and enhance education, learning and research as well as service and administrative functions all

\footnotetext{
${ }^{1}$ A recent study published by UNESCO [11] indicates that at least 15 of 28 countries included in the study have developed a specific policy for training IT/S professionals.

${ }^{2}$ One great step here has been the publication of A curriculum for an information society: educating and training information professionals in the Asia-Pacific region [17]. However, it is notable that the gap has not been narrowed since then.
} 
over the country. Strategies and policies for using ICT are developed by the Supreme Council of ICT (chaired by the President) and the responsibility for carrying out strategies rests with The National ICT Agency.

The emphasis on human resource development as "the strategic priority" in TAKFA objective statement clearly shows that education and learning play a central role in country's ICT development policy [15]. There are specific policies written for developing information literacy, general information-handling skills (technology use) and training IT/S professionals. ${ }^{3}$ These policies include, but are not limited to, providing basic ICT training for government employees, integrating ICDL training into school programmes and developing ICT-related degrees at university level.

In the same year, the Iranian Centre for Research in Telecommunications, under the then Ministry of Post, Telegraph and Telephone (PTT) ${ }^{4}$, issued the National Strategy for ICT Development which was the result of an outsourced study on the prospect for developing ICT within the country [13]. This study highlighted the importance of human resource development and the need for developing new university programmes to educate adequately skilled IT/S professionals. The study also emphasised the need for a quantitative estimation of the number of IT/S professionals needed in near future.

The following year, a follow-up study was done on human resource development [14]. Looking at a five year horizon, the study assumed that the difference between vacant ICT-related careers evolving in this period and the number of graduates in ICT-related fields was to be filled by the professionals trained in the new ICT departments. ${ }^{5}$

Broadly speaking, the Iranian system of higher education consists of a relatively large number of state universities and a number of non-state universities (including a fee-charging university with many branches across the country, a distance learning university, a few recently established private universities and very few research institutions). These all are accredited by the Ministry of Higher Education.

The Ministry of Higher Education is also responsible for designing the standard curricula of degrees and syllabi of courses for all degrees. Since 1981, a prospectus for every programme must be proposed to the Supreme Council of

\footnotetext{
${ }^{3}$ The information regarding policies for training IT/S professionals is missing from Moore's report [11]. This may be the result of desk-based research approach of the study which has limited the sources of information to those available through the internet. But the study names Iran (along with some other countries like Japan) as "notable exceptions" which "take a broader view and aim to raise the level of information technology literacy throughout the population" in information literacy policy. The country is also recognised for requiring all government employees to have basic levels of ICT skills in order to develop ICT handling skills of the workforce.

${ }^{4}$ The ministry is now called the Ministry of Communication and Information Technology.

${ }^{5}$ It must be stressed here that neither TAKFA nor The National Strategy for ICT Development had not neglected the role of subsidiary educational institutions (such as technical and vocational training schools) in the training of ICT technicians as part of the IT/S professionals; but since we have focused our analysis on the role assumed for the universities in this process of development, we concentrate on sections in these policies that address this issue.
} 
Higher Education Planning. This council will revise the programme and forward it to the Supreme Council of Cultural Revolution for final approval. ${ }^{6}$ All accredited universities must follow the approved standard. Although no formal inspection has ever been made to check the conformity of the actual teaching process, the standard is followed with minor deviations in almost all universities' classes across the country. Most currently used curricula and syllabi were developed around 1982-1983, with only minor revisions since.

In this context, the Ministry of Higher Education was obliged to develop ICT departments covering both undergraduate and postgraduate levels in ten universities [15, Section 3.2.1]. As a prerequisite, the ministry assigned the BTF Institute to the task of designing a standard ICT department to be adopted in those universities. The project was initiated in late 2003.

\section{The case}

A team of some 15 researchers was formed to execute the project. The first question to be addressed was "What is meant by an ICT department?" To answer the question, some 20 departments of IT were selected and studied along with other schools that provided some degrees in IT but did not have the title of "IT Department" or the like, notably business schools offering degrees in IT management. Other forms of ICT education at university level were also considered, such as the Multimedia University in Malaysia. The aim was to develop an understanding of alternative models of providing university-level ICT education and alternative forms of ICT departments and to find the most suitable model for Iranian universities. For reasons beyond the scope of this chapter, the choice was made to rename existing Computer Engineering departments to Computer Engineering and Information Technology departments and to extend their curriculum to offer technical degrees in ICT. Degrees in IT management were to be handled by business and management schools.

The next question was "what is taught in an ICT department?" There are differences between the standard curriculum in the sense described above and "model" curriculum discussed, for example, in [12]. However the methods for designing both are similar. Thus, this simple question led the team to study the curriculum of some selected departments. It is notable that Iranian universities do not award two-year associate degrees and therefore the search was limited to fouryear undergraduate and postgraduate degrees. ${ }^{7}$ To make a comprehensive review, the team explored in full detail the syllabus of every single course in relevant departments which in some cases included reading laboratory manuals. There was an incredible diversity of approaches to the subjects and the offered courses varied substantially from one department to another. Every department had its own selection of topics. Even for topics with the same title, two very different

\footnotetext{
${ }^{6}$ It was in 2005 that universities acquired the authority to revise course syllabuses or add new courses.

${ }^{7}$ The associate degrees are awarded by technical and vocational training schools.
} 
approaches were pursued. This posed the third question "what should Iranian universities teach in ICT-related areas?" This included both designing new courses and redefining the existing ones which were taught at computer engineering departments.

Up to that time, no qualitative assessment of ICT education needs was made at national level. No information was present to make decision about which aspects of ICT to emphasise and which aspects to neglect or deemphasise. It was suggested by the author to map ICT-related careers against the national ICT plans to find out which careers are most required and which knowledge and skills must the future IT/S professional posses to perform his/her job competently.

This approach was criticised for undermining the role of private sector, but it was argued that the government will have the leading role in the diffusion of ICT in medium term and most private companies will be just contractors of governmental projects. This meant that they were to a large degree dependent on the government initiatives. Indeed, according to TAKFA, the government was obliged to provide support for the establishment of 500 ICT-related companies. Furthermore, the approach could help the planning of IT/S professionals' education by providing the time frame within which certain skills were needed. For example there was an immediate need for network-related professionals to support the development of national information network infrastructure. But postgraduate programmes in e-business and e-commerce were not needed until some 3 or 4 years later when e-business development plans would get underway.

The absence of a clear link between IT/S professionals' training programmes and their role in national ICT development has been a basic deficiency in most IT/SPTPs. Moore reports that most Asian countries follow what Walsham [18] calls the "standard route" in developing human resources, i.e. awarding ICTrelated degrees [11] (for some exceptions, see Carayannis and Sipp [3]). Thus they usually have serious shortcomings regarding the inclusion of these trained specialties in the actual creation, manipulation, processing and use of information in society. By matching IT/SPTP to other national ICT development plans, the vision would become clear for future IT/S professionals.

Subsequently, the author was appointed as the manager of internal studies' group in mid 2004 and the team started to research about 1) knowledge and skills required for each career and 2) careers and job titles associated with implementation of ICT plans. The results were fascinating because they closely matched the previous quantitative studies and provided a plausible basis for designing the curriculum $[9,10]$. But just then it seemed that further progress of the project was blocked by a number of overseen problems.

First, it was realised that the curriculum would have a short life, its material will soon be outdated and it will need to be revised. Given the resistance of the existing computer engineering departments to revise the obsolete course syllabi, this problem was not negligible. Moreover, revising the syllabus (of even one course) through the centralised mechanisms described above was not an easy task. 
How should the process begin, who would decide about it and who would have the capabilities to revise the syllabus?

Second, such unified curriculum did not allow space for local peculiarities and regional differences. The spread of ICT was uneven and different provinces needed different combinations of skills and trainings [13]. Some flexibility had to be added into the system to allow some level of adaptation to local priorities.

Third, Walsham [18] points to the lack of broader social skills and capabilities in university graduates of computer sciences (in the most general sense of the word) due to the fact that their formal education focuses almost exclusively on technical training. This results in major difficulties when these graduates are introduced to the workplace, especially in developing countries.

Last but not least important, finding qualified lecturers seemed to be a very difficult task. Most of the current faculty members and people with formal educational backgrounds did not have the necessary background to teach new courses. Those who had technical qualifications to teach new courses did not have the educational background necessary to be faculty members. Very few individuals had both competencies and these could not be easily reached.

\section{Discussion}

At this point, the reader may reasonably suggest: "Well, you did not have to abandon the project. A change of direction would have sufficed." But these obstacles jeopardised the vision of ICT department and blocked further investigation into the structure of department, its connections with other departments and etc. In fact, the practical obstacles were important but they were not the sole reasons for the early termination of project. The project was never formally dropped, but literally abandoned.

In this section a number of solutions for the above-mentioned obstacles are presented, followed by a discussion of their practical implications. The interrelationship of these problems and the paradoxical role of a centralized higher education system in regard to IT/S professionals' training are also highlighted.

\subsection{The challenge to the centralized higher education system}

It seems that little can be done in respect of the first issue, i.e. the short life of the curriculum. The fast changing nature of information technology and its unpredictability have proved to be an essential problem contributing to this issue. However, one strategy can be dividing the curriculum into core and non-core subjects, giving more persistence to courses with more fundamental importance [16, p. 29].

The slowness and complexities of bureaucratic mechanisms can be removed from the system by giving more authority to universities themselves. The situation here is very much like the classical distinction of centrally planned (bureaucratic) structure and market structure in organisation theory (see for example $[4,8]$ ). 
While the former is maintained through authority controls, the latter reacts to the dynamics of supply and demand, being coordinated by the communication of a "sufficient statistic" (e.g. price) which contains all the information one needs for decision making.

To draw more on organisation theory, one possible middle ground can be Sloan's Multidivisional form (or more shortly, the M-form). The M-form structure was essentially designed to simplify decision making structures within large firms [7]. By separation of strategic and operational issues, each division had more independency regarding its own operational and tactical decisions while committing to achieve some financial targets specified by central management team. The central management team, on the other hand, had more free time to investigate strategic issues and look at further horizons.

Such an approach can be very helpful in the context of national higher education system that faces the challenges discussed here. Universities can have some degree of freedom, given that they will not fall short of some educational standards. The policy makers can take a broader and strategic perspective on course selection as well as paying more attention to the issues concerning the whole higher education system. This is in line with our previous recommendation to divide curriculum into core and non-core courses and it perfectly matches the need for flexibility in adopting the curriculum for different provinces of the country.

If such implementation is not possible in the short run, it may be more appropriate to rely on more flexible options like non-degree programmes or vocational training certificates. This is particularly relevant if finding/training qualified lecturers are difficult or uneconomical (see below). For some specialties, it may be sufficient to invite professionals or, more appropriately, "professional services" from other countries. This is practical especially when some expert opinion is needed, as in the evaluation of the human-computer interface of a nation-wide system. Experts, by definition, will evolve through practice and expert-level practice cannot be included in formal education. But in sensitive areas such as system securities some cautionary measurements must be in place when relying on foreign professionals. However, it must be emphasised that in the long run, countries have to move to more flexible mechanisms in order to enjoy the full benefits of a dynamic and progressive national ICT development.

\subsection{The challenge of IT/S professionals' social skills}

To enhance the social and organisational capabilities of IT/S professionals, one simple option is to improve the curriculum by including some courses on social relationships. But a more challenging option is to re-skill the alumni of universities through continuing education courses held at universities. Alumni have the advantage of possessing practical experience and basic familiarity with the field. This can be effectively exploited to shorten the duration of specialised qualifications to less than one year. This re-skilled workforce who is equipped 
with both reliable theoretical knowledge and practical skills can be quickly absorbed for urgent needs of society while others are in preparation in formal undergraduate programmes.

Walsham [18] also mentions the shortage of senior IT/S professionals in developing countries who can help newer recruit to learn some of the organisational and behavioural skills and knowledge. These re-skilled professionals can also fill this shortage. Such continuing education programmes can also take the form of lifelong learning programmes which is of essential necessity for IT/S professionals but is often missing in the IT/S professionals' training policies.

\subsection{The importance of national language}

Finding qualified lecturers is a much more complex process than one might think. Here the language spoken in academic environments becomes of central importance. If it is English, French, Spanish or Portuguese (i.e. the languages which have many speakers around the world and particularly in the developed countries) it would be relatively easy to find foreign lecturers teaching in your language. But if the national language is relatively local with few or no speakers in the developed countries, it will be very difficult to find suitable lecturers. In fact, except for lecturers from your own country living abroad, there will be very little chance to find anyone and again it is very hard to attract these people.

One alternative strategy can be initiation of bilingual education, i.e. to lecture some courses in local language and some other in a foreign language; English for example. Thus you can invite and recruit foreign lecturers, bringing fresh air and dynamism to your academic environment. In Iran, the National Strategy for ICT Development had suggested moving towards the "bilingual-isation" of educational system, but broader policies regarding protection and propagation of the national language did not permit such ideas to be materialised.

Another alternative can be training of existing or potential faculty members by foreign lecturers (in a second language) and then assigning them to lecture on those topics in the local language. This approach seems to be the most practical solution because it makes existing faculty members more interested and poses the least threat to the national language. However, this option is usually expensive and time consuming.

Yet another option, more practical but more effectively limited, is to provide overseas education bursaries. The graduates of such programmes, usually with postgraduate degrees and up-to-date knowledge, are usually valuable potential candidates as faculty members and can be very helpful for the restructuring of ICT-related education in universities. However, their ultimate effectiveness is severely limited to the appropriate revision of curriculum to which they can be valuable contributors.

As it is clear from this discussion, these challenges are highly interrelated and policy makers must take a holistic view to understand the circumstances in full 
and plan accordingly. However, central to these challenges is the centralized planning system upon which higher education is heavily dependent in most developing countries. The centrally planned educational system is the primary institution by means of which governments are involved in implementing IT/S professionals' training policies. Hence, the governments have to "act upon" this system in apparently contradictory ways: on the one hand to supply the whole country with adequately skilled workforce in the long run and on the other to introduce more flexibility to the higher education system to cope with regional and temporal demands. While most countries pay considerable attention to the former issue, little attention is paid to the critical and vital role of the second in the long run. This is the subject we turn to in the next section.

\section{Retrospective view}

Now, with the benefit of hindsight, a reconsideration of the general themes and implicit assumptions underlying TAKFA and other nation-level plans can be valuable. Surely, these plans were criticised on a number of grounds at that time but in most cases these criticisms were limited to sectoral boundaries such as egovernment and e-health. In rare cases the whole policy was assessed. These evaluations usually attacked methodological aspects of national ICT policies (for example [2]), its technological implications or even the adopted privatisation policies. It is interesting, however regrettable, that both policy makers and critics were considering IT/S professionals' training as business-as-usual and, except for the "brain drain" problem, little attention was paid to the challenges of IT/S professionals' training in the higher educational system.

In TAKFA, the section on development of ICT in higher education consists of three elements: developing a network between universities, developing universitylevel ICT degrees and supporting ICT-related research in universities. ${ }^{8}$ The policy also calls for a revision of university-level degrees based on the capabilities of ICT [15, section on The Second Step Plan]. No specific mechanism or advice is suggested for accomplishing any of these tasks. Expectedly, no potential practical obstacle has been addressed. Moreover, given the relatively successful centralised approach of the Ministry of Higher Education in planning and directing education in society, no adjustment of the usual approach was considered.

The National Strategy for ICT Development calls for a differentiation of ICTrelated degrees in order to facilitate the planning of the IT/S professional workforce and puts more emphasis on vocational training of ICT technicians. However, it is interesting that it highlights "the existence of capable human resources and the growth ICT-related graduates" in the country as a point of strength [13, p.132]. This is despite the tiny size of ICT industry (less than 500

\footnotetext{
${ }^{8}$ Other sections on education consists of: developing the ICT infrastructure of schools and connecting them through a network, training the general public (most notably teachers and government employees), and developing e-learning and multimedia-enabled courses for the schools.
} 
companies in 2001 and an estimated 210,000 employees overall, including the government employees in the ministry of PTT) and the inadequacies of appropriately trained IT/S in the workforce [2]. The report gives no guideline for training IT/S professionals except briefly mentioning the need to estimate the number of IT/S professionals needed and for continuous curriculum revision.

The subsequent report on human resource development has a more realistic picture of the workforce and explicitly concerns "the shortage of IT/S professionals" and "the lack of practical skills in existing professionals". The report also mentions the shortage of competent lecturers and the gap between the current curriculum and the actual needs of ICT sector [14]. However, it makes no reference to the need for regular curriculum revision and its challenge to the centralised approach of the ministry of Higher Education.

These reports give much less attention to the other challenges of IT/S professionals' training. As noted before, the National Strategy for ICT Development advocated the bilingual-isation of the educational system. It also briefly mentioned the need for more cooperation between industry and universities, but in both cases it did not provide any specific mechanism or guideline. This may be in part due to a lack of any institutionalised mechanism for cooperating with industry or to get any feedback from them which by no means is limited to only ICT-related degrees. This may be compared to the following recommendation made by the ACM Two-Year College Education Committee in its 'Guidelines for Associate-Degree Programs to Support Computing in a Networked Environment':

Colleges should keep plans current through a comprehensive plan that includes ongoing professional growth and development for faculty and staff, continuous curriculum revision, periodic review, assessment and replacement of equipment and associated resources, and ongoing evaluation and updating of instructional methodologies and teaching materials.... An active industry advisory council, together with ongoing feedback from graduates and employers, provides an important mechanism to ensure that this occurs. These industry partnerships can provide many forms of support to the twoyear college, including curriculum advice, industry training materials, in-service opportunities for faculty, a source of adjunct faculty, equipment donations, supplemental funding, student internships, placement opportunities, and recognition of program excellence [1].

Indeed, if such mechanisms had been in place, the curriculum would have been much more up-to-date and the centralised approach would have been enhanced by periodical quantitative and qualitative feedbacks from the industry. This would have also enabled the curriculum design project to be conducted in a much more flexible and demand-based manner. In the absence of such facilitating mechanisms, policy makers must clearly distinguish between what seems possible and what should actually be done. 


\section{Conclusion}

This chapter critically examined some conventional ideas about the training of IT/S professionals and the roles of universities in this regard. Drawing on a dropped ICT curriculum design project, the challenges of ICT education to the traditional higher education structure were explored. Several points can be drawn from the discussion presented.

One obvious message of this chapter is that developing university-level degrees for training IT/S professionals through standard rigid curriculum is not advisable. IT/S professionals' training is different from ICDL training. While central planning may be effective for developing information literacy and general information handling skills, it poses several challenges to the effective training of IT/S professionals. More often than not, central planning is conjoined with obstructive bureaucracies of higher education which dislike changes and cannot adapt to the rapid developments of the IT/S field. The M-form was suggested as a solution to some of these problems. However, it was suggested that four-year university degrees may not be the best options for educating IT/S professionals in some developing countries, at least for the short run. Policy makers must think out of the box and look for creative options. The opportunities provided by re-skilling the available workforce should not be overlooked.

Another message is that in line with Walsham and Moore, we suggest that policy makers must specify which ICT-related professions are needed and by how much. In other words, they must clarify how these trained specialists will be included in country's ICT development plans. This can lead to a categorization of the required IT/S professionals, their (possible/preferred) supply sources (including university education, vocational training, re-skilling programmes, and service importation contracts) and necessity time frames. This level of integration in the national IT/SPTP can give the graduates a clear vision of future and thus can contribute to maintaining graduates within the country, i.e. restricting the scale of brain drain phenomenon.

A third message is that policy makers must take into account the realities of available IT/S professionals especially in the academic environments before making any decision regarding further development of human resources. The role of language as a social phenomenon directly affecting the access to IT/S professionals and lecturers and the importance of public policies in this regard cannot be overstated.

\section{Acknowledgements}

The members of the research team, one and all, had valuable contributions to both the process and the goal of the research. The author appreciates their efforts without which this chapter would never be possible. The author also wishes to express his appreciation to the two anonymous reviewers for their constructive comments. 


\section{References}

[1] ACM Two-Year College Education Committee (2000). Guidelines for associatedegree programs to support computing in a networked environment. Rockford, Illinois.

[2] BTF Institute (2002). A critique of national ICT policy and strategies. BTF Institute, Tehran, Iran.

[3] Carayannis, E.G., \& Sipp C.M. (2006). E-development toward the knowledge economy, New York: Palgrave Macmilan.

[4] Coase R.H. (1937). The nature of the firm. Eonomica, Vol. 4, 386-405.

[5] Fekri, M., \& Jahangir M.R. (2004). The role of ICT department in planning and developing human resources. Proceedings of the Second International Management Conference (IRIMC 2004), Tehran, Iran.

[6] Grant G. (ed.) (2001). Regional initiative for informatics strategies. COMNET-IT and The Commonwealth Secretariat.

[7] Gullien M.F. (1994). Models of management. Chicago: The University of Chicago Press.

[8] Hayek, F.A. (1945). The use of knowledge in society. American Economic Review, 35(4), 519-30.

[9] Honarvar, R., Jahangir M.R., \& Rezaei A. (2003a). Report on shortages in current national ICT education, BTF Institute. Tehran, Iran.

[10] Honarvar, R., Jahangir M.R., \& Rezaei A. (2003b). A comparative study of ICT human resources. BTF Institute, Tehran, Iran.

[11] Moore N. (2005). Information policies in Asia: A review of Information and Communication Policies in the Asia Region, Communication and Information in Asia. Bangkok: UNESCO.

[12] Noor, A. El Sayed (1984). Towards a model curriculum in computer-based information systems for developing countries: The case of Arab environments. Computers and Education, 8(2), 239-62.

[13] RADSAMANE (2002). National strategy for ICT development. Tehran, Iran.

[14] RADSAMANE (2003). Studies on human resource development. Tehran, Iran.

[15] Supreme Council of ICT (2002). TAKFA: extension of application of ICT in Iran. Tehran, Iran.

[16] The Joint Task Force for Computing Curricula 2005 (2005). Computing curricula 2005: the overview report. ACM and IEEE. United States of America.

[17] UNESCO (1998). A curriculum for an information society: Educating and training information professionals in the Asia-Pacific region. Bangkok: UNESCO.

[18] Walsham, G. (2000). IT/S in developing countries. In M. Zeleny (ed.) (2000) The IEBM Handbook of Information Systems in Business (pp. 105-109) London: Thomson-Learning. 